\title{
COMPARISON ANALYSIS AMONG DIFFERENT CALCULATION METHODS FOR THE STATIC STABILITY EVALUATION OF TAILING DAM
}

\author{
M. $\operatorname{Li}^{1}$, L. Liang ${ }^{1}$, X. $\operatorname{Li}^{1}$
}

${ }^{1}$ Research Institute of Civil Engineering, College of Resources and Civil Engineering at the Northeastern University (liming-neu@163.com)

\begin{abstract}
The static stability evaluation of tailing dam is one of the most important tasks in the mine environmental protection project. The methods for the static stability calculation were discussed in this paper, which were Swedish Circle Method, Janbu Method, Bishop Method, Finite Element Method and Strength Reduction Finite Element Method (SRFEM) with five different failure criterions considered. The analysis results show that the failure surface simulated by SRFEM was closed to the result of classical method, and the safety factor by SRFEM with D-P3 failure criterion was much more closed to the one got from the Fellenius Method. So, it is feasible to evaluate the static stability of tailing dam through SRFEM. Also, it indicates that the finite element method and SRFEM are suitable to simulate practical engineering with the complicated cross section and non-linear materials.
\end{abstract}

Keywords: Tailing dam, SRFEM, Static stability evaluation.

\section{INTRODUCTION}

The static stability analysis for tailing dam was started from 1930s using the limit equilibrium method originated from soil mechanics. After the finite element method was put forward in 1966, Clongh and other researchers started the strain and deformation analysis for earth dam. Then the Finite Element Method (FEM) was used for the evaluation of tailing dam. Till now the limit equilibrium method and strain stress analysis method are widely used in the static analysis of tailing dam and those methods were theoretically improved.

There were many factors which influenced the stability of tailing dam, such as material strength, ground water conditions and pore water pressure. However, there is no independent analysis system for tailing dam. All of the methods were from soil mechanics, such as Swedish Circle Method (1936), Janbu Method (1957), Bishop Method (1955), MorgensternPrice Method (1965), Spencer Method (1967) and Sarma Method (1973). The main differences between those methods were the shape of failure surface and treatment for unknown variables.

Another important method for the static stability analysis is the finite element method. By this method, the stress distribution, the force in weak structure surface and failure could be got. Based on the finite element method, there were two different methods which were elastic- 
plastic finite element method and strength reduction finite element method (SRFEM). The latter one is more popular now. Zheng Y. R. and Zhao S. Y. (in China) make great contributions to this method in theoretical research and its engineering applications [1-5].

In this paper, the comparative analysis for the static stability analysis of tailing dam was carried out by the Swedish Circle Method, Janbu Method, Bishop Method, Finite Element Method and SRFEM.

\section{METHODS FOR STATIC STABILITY EVALUATION OF TAILING DAM}

\subsection{Traditional Method}

The limit equilibrium method was based on the theory of Mohr-Coulomb. The function was

$$
\tau_{f}=c^{\prime}+\sigma^{\prime} \tan \phi^{\prime}=c^{\prime}+(\sigma-u) \cdot \tan \phi^{\prime}
$$

Where $\tau_{f}$ is the shear stress on the slide surface, $c$ is the effective cohesion, $\sigma$ is the total stress, $\sigma^{\prime}$ is effective normal stress, and $\phi^{\prime}$ is the effective internal friction.

The safety factor was defined by the ratio of $\tau / \tau_{f}$ which stands for the strength reserve coefficient for materials. Only the static stability conditions and Mohr-Coulomb failure criterion were considered in this method. There were many advantages for this method such as simplified calculation and easily used in practical engineering. But the relationship between stress and strain of soil cannot be got from this method. The three main methods based on the limit equilibrium method were Swedish Circle Method, Janbu Method and Bishop Method.

For the static stability analysis of this project the limit equilibrium methods were used through the Civil FEM module in ANSYS. The safety factors and slide surface can be got easily by this module.

\subsection{Finite Element Method}

\section{(1) Finite Element Method}

The stress and strain distribution of the whole tailing dam can be simulated by FEM. The first step was to get the value of each element. Then the stress distribution in each potential slide surface can be calculated through the transform of stress tensor. According to the concept of limit equilibrium method, the safety factor of each potential slide surface can be got [6-7].

(2) Strength Reduction Finite Element Method

The secondary development language APDL in ANSYS was used for the programming of SRFEM, because there is no existing module for this method. This program contains five main parts. (1) Create the finite element model and input material parameters. (2) Apply the loads and boundary conditions. (3) Set solution settings and input initial condition for rou- 
tine. (4) Get the reduction factors and the displacement curve on the top of dam. (5) According to the curve of displacement and reduction factors, obtain the safety factor of tailing dam.

There are two instability criterions for SRFEM. One is when the FEM calculation is non-convergence. The other is when generalized plastic strain or equivalent plastic strain areas were connected from the toe to the top of the slope. According to the reference [8-9], the former one was thought to be much more reasonable for slope stability and it was used in this paper as the tailing dam instability criterion.

There are three parameters for Drucker-Prager (D-P) criterion in ANSYS. They are internal friction angle $\varphi$, cohesion c and dilatancy angle $\psi$. If $\psi=\varphi$, the rule is associated flow rule. If $\psi<\varphi$, the rule is non-associated flow rule.

In the ANSYS, the criterion is D-P1 criterion [10-11]. It means that the safety factors got from ANSYS was under D-P1 criterion. However, there are totally five different D-P criterions which can be converted using equation (2). By input different $\alpha$ and $\mathrm{k}$, the equivalent c, $\varphi$ can be got and used for the simulation without extra secondary development for new material model.

$$
\left\{\begin{array}{c}
\varphi_{1}=\arcsin \frac{3 \sqrt{3} \alpha_{i}}{2+\sqrt{3} \alpha_{i}} \\
c_{1}=\frac{\sqrt{3} k_{i}}{2 \sqrt{\left(1+2 \sqrt{3} \alpha_{i}\right)\left(1-\sqrt{3} \alpha_{i}\right)}}
\end{array} \quad(i=1,2,3,4,5)\right.
$$

Where $\alpha$ and $\mathrm{k}$ are separately related with internal friction angle and cohesion. For different D-P criterions, $\alpha$ and k represented different circle in $\pi$ plane [11].

\section{BACKGROUND OF PRACTICAL ENGINEERING}

The height, width and length of tailing dam were separately $19 \mathrm{~m}, 14 \mathrm{~m}$ and $113 \mathrm{~m}$. The initial dam was constructed by sand stone mixtures. The sub dam was constructed by tailings and soil. The soil thickness covered in the dam surface was from $300 \mathrm{~mm}$ to $500 \mathrm{~mm}$. There were 11 sub dams with $2 \mathrm{~m}$ height each. The dam scene photo and section selected for calculations of this dam were shown in Fig. 1.

According to the mechanical model shown in Fig. 1, the finite element model was created and meshed shown in Fig. 2. The boundary conditions were added including horizontal constraints in both two sides, and full constraints in the bottom of the model. The load applied in this model was only gravity. The material parameters for calculation were listed in table 1. 

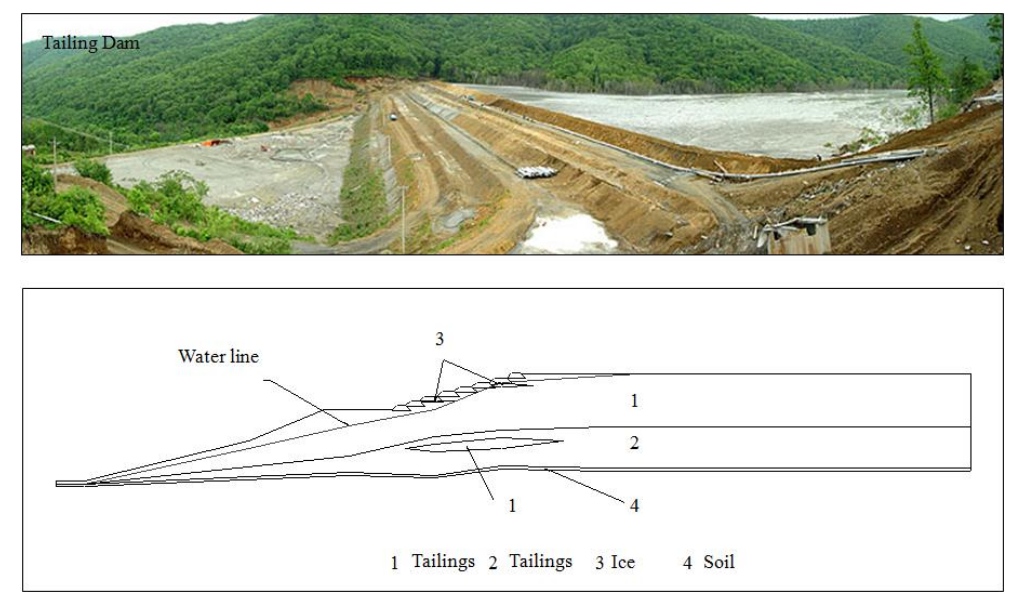

Fig. 1 The scene photo and section for calculations

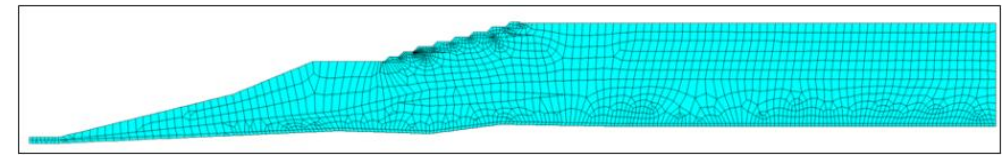

Fig.2 Finite element model of tailing dam

Table 1 Mechanical properties of material

\begin{tabular}{ccccccc}
\hline Material & Material & $\begin{array}{c}\text { Gravity } \\
\text { nensity } \\
(\mathrm{kN} / \mathrm{m})\end{array}$ & $\begin{array}{c}\text { Compression } \\
\text { modulus } \\
(\mathrm{MPa})\end{array}$ & Poisson ratio & $\begin{array}{c}\text { Cohesion } \\
(\mathrm{kPa})\end{array}$ & $\begin{array}{c}\text { Internal } \\
\text { friction } \\
\text { angle } \\
\left({ }^{\circ}\right)\end{array}$ \\
\hline 1 & $\begin{array}{c}\text { Silt sand of } \\
\text { tailing } \\
\text { Silt soil of } \\
\text { tailing }\end{array}$ & 18.4 & 10.9 & 0.3 & 4.2 & 24 \\
2 & 19.5 & 10.4 & 0.35 & 23.8 & 20 \\
3 & $\begin{array}{c}\text { Ice layer } \\
\text { Natural soil }\end{array}$ & 16.2 & 4.5 & 0.4 & 0 & 5.6 \\
\hline
\end{tabular}

\section{RESULTS FROM DIFFERENT METHODS}

The static stability factors were directly calculated by limit equilibrium method and finite element method using Civil FEM module in ANSYS software. The strength reduction finite element method was realized through the secondary development language APDL of ANSYS.

The slide surfaces got from tradition limit equilibrium method and failure areas calculated by SRFEM were separately shown in Fig. 3 and Fig. 4. The safety factors were listed in table 2 and table 3. 

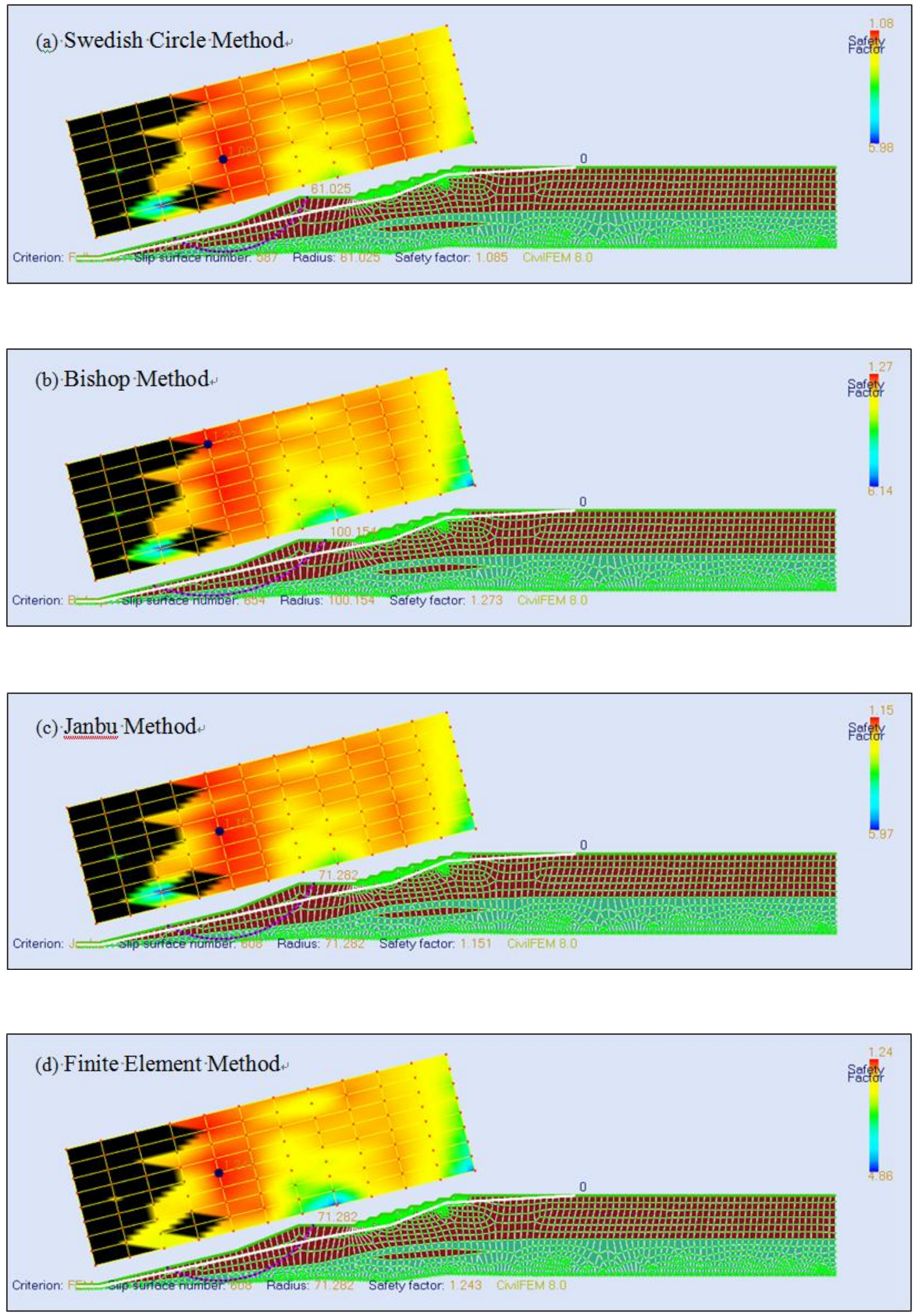

Fig. 3 Typical slide surface from traditional method 

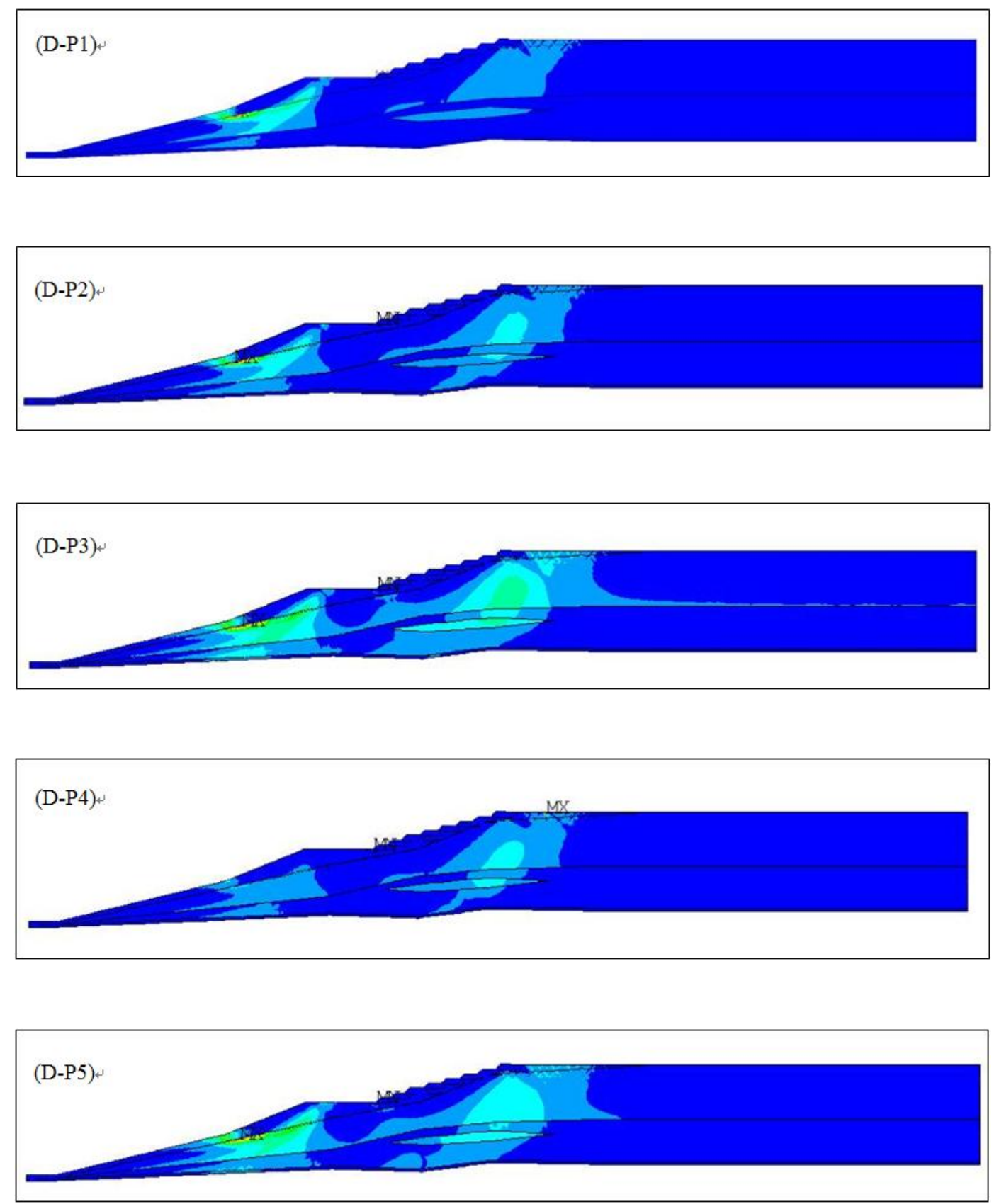

Fig. 4 The failure surface calculated by SRFEM with different D-P criterions

Table 2 Safety factors calculated by tradition limit equilibrium of tailings dam

\begin{tabular}{ccccc}
\hline Method & $\begin{array}{c}\text { Swedish } \\
\text { Circle Method }\end{array}$ & $\begin{array}{c}\text { Bishop } \\
\text { Method }\end{array}$ & Janbu Method $\begin{array}{c}\text { Finite element } \\
\text { method }\end{array}$ \\
\hline Safety factors & 1.085 & 1.273 & 1.151 & 1.243 \\
\hline
\end{tabular}

Table 3 Safety factors calculated by SRFEM with different D-P criterions

\begin{tabular}{lccccc}
\hline D-P criterions & D-P1 & D-P2 & D-P3 & D-P4 & D-P5 \\
\hline Safety factors & 1.56 & 1.26 & 1.17 & 1.12 & 1.24 \\
\hline
\end{tabular}




\section{RESULTS COMPARISONS}

The potential slide surfaces calculated by the traditional method were almost the same which were all in the initial dam. The smallest safety factor was the one got from Swedish Circle Method.

From the study of strength reduction finite element method, the ideal elastic-plastic model was selected for the static stability calculation of tailing dam. The results show that it was feasible and superior to calculate safety factor by SRFEM.

With the different D-P criterions, the slide surfaces were basically identical and they were closed to the traditional method. The factor simulated by D-P1 criterion was the biggest. The other four factors were much closed to those by traditional method and finite element method.

The plastic strain areas calculated with D-P3 and D-P5 criterion were connected from the toe to the top of the initial dam. The potential slide surface calculated with D-P3 criterion was much more closed to the one by limit equilibrium method, shown in the Fig.3. So the safety factor with D-P3 criterion was recommended for the static stability evaluation of tailing dam.

\section{CONCLUSIONS}

The traditional limit equilibrium method, finite element method and strength reduction finite element method were introduced in this paper. From the results comparison analysis among different methods, the following conclusions can be got.

(1) The SRFEM was feasible for the static stability evaluation for tailing dam.

(2) From the safety factors and slide surface comparison among different calculations methods, the D-P3 criterion was more priority if the SRFEM was used for the static stability evaluation of tailing dam.

\section{Acknowledgements}

This study is supported by Safety Diagnose Technique and Control Countermeasures of Tailing Dam, Research Institute of Civil Engineering, Northern University, China.

\section{REFERENCES}

[1] Zheng Y. R., Zhao S. Y., Song Y. K., "Advance of study on the strength reduction finite element method". Journal of Logistical Engineering University. 3, 1-6, 2005.

[2] Zheng Y. R., Zhao S. Y., "Application of strength reduction fem in soil and rock slope”. Chinese Journal of Rock Mechanics and Engineering. 19, 3381-3388, 2004.

[3] Dawson E. M, Roth W. H., Drescher A. "Slope stability analysis by strength reduction”. 
Geotechnique. 49, 835 840, 1999.

[4] Jiang G. L., Magnan J. P., "Stability Analysis of Embankments comparison of limit analysis with methods of slices". Geotechnique. 47, 857-872, 1997.

[5] Wan S. H., Nian T. K., Jinag J. C., Luan M. T. "Discussion on several issues in slope stability analysis based on shear strength reduction finite element methods". Rock and Soil Mechanics. 7,2283-2316, 2010.

[6] Zou J. Z., Willianms D. J., Xiong W. L., "Search for critical slip surface base on Finite Element Method”. Canadian Geotechnical Journal. 32, 233-246, 1995.

[7] Griffiths D. V., Lane P. A., "Slope stability analysis by finite elements". Geotechnique. 49, 387-403, 1999.

[8] Zhao S. Y., Zheng Y. R., Zhang Y. F., "Study on slope failure criterion in strength reduction finite element method". Rock and Soil Mechanics. 26, 332-336, 2005.

[9] Zhao S. Y., Zheng Y. R., Liu M. W., Qian K D. "Definition and transformation of slope safety factor based on drucker-prager criterion”. Chinese Journal of Rock Mechanics and Engineering. 25, 2730-2734, 2006.

[10] Liang L., LI M., WANG W., CHEN Bao-zhi. "Numerical analysis method of tailing dam stability”. Journal of Safety Science and Technology. 5, 11-15, 2007.

[11] Li M., Liang L., Wang W., LIU Dongxia. "Study on antiskiding stability safety factor of dam slope by shear strength reduction finite element methods". Journal of safety science and technology. 2, 83-86, 2012. 